Article

\title{
Improving Understanding of City Spaces for Tourism Applications
}

\author{
Kheir Al-Kodmany \\ Department of Urban Planning and Policy, College of Urban Planning and Public Affairs, University of Illinois at \\ Chicago, Chicago, IL 60607, USA; kheir@uic.edu
}

Received: 25 June 2019; Accepted: 12 August 2019; Published: 15 August 2019

\begin{abstract}
This paper explores a blend of digital and traditional methods to inform about a city's popular spaces. Using locational data from social media platforms including Twitter, Facebook, and Instagram, along with using participatory field surveys and direct observations and combining insights from architecture and urban design literature, this study reveals popular socio-spatial clusters in the city of Chicago. The locational data of photographs were visualized by using geographic information systems, and they helped in producing heat maps that showed the spatial distribution of posted photographs. The geo-intensity of photographs illustrated the areas that are the most visited in the city. The study's results indicate that the city's most popular places include Millennium Park, Maggie Daley Park, Navy Pier, the Magnificent Mile Gateway, the Inner Loop, the Water Tower Area, the River Confluence, Museum Campus, Urban Giants, Grant Park, and the River City complex. The findings elucidate that social media plays an important role in promoting places and thereby sustaining a greater interest and stream of visitors. Consequently, planners should tap into the public's digital engagement in city places to improve tourism and the economy.
\end{abstract}

Keywords: social media; digital photographs; big data; spatial perception; city life; tourism

\section{Introduction}

\subsection{Goals and Scope of Work}

The presented study aims to explore combinations of research methods for information about the evaluative image of a city. It specifically intends to uncover the spatial dynamics of open spaces and tall buildings. While the former takes a horizontal stretch, the latter embraces verticality. The research hypothesizes that the art of skyscraper spatial juxtapositioning with open spaces is understudied, and planners should re-examine high-rise cities to learn about these spatial relationships. Chicago is the birthplace of skyscrapers and has been praised for its sound urban design and architecture as well as its plazas and open spaces. Consequently, it is a good case study for examination. After reviewing established inquiry methods used by prominent scholars, the study builds on their work and engages a blend of digital and traditional tools to gather and analyze data related to urban spaces, their values, and their contribution to the quality of life in the city of Chicago.

In the past decade, many cities have increasingly been using digital methods for gathering and analyzing data or "Big Data" to better understand urban experiences. In his research on cyburban semiotics, Timothy Jachna explained, "The superimposition of digital technologies upon the physical space of the city is restructuring the urban experience and overriding or altering urban semiotic systems and patterns" (2004) [1]. According to Jachna, communication media enabled by the cellular phone network and the Internet pose the challenge of changing the way cities are understood, lived in, and experienced. Therefore, tapping into continuously generated data, or "Big Data", is a useful project that updates and informs about ways to improve existing conditions and experiences. A continuous 
flow of data reflects changing city life in real time, illustrates emerging urban patterns, and grants new perspectives on urban activities [2]. As such, this research intends to take advantage of new digital tools as well as traditional methods of inquiry.

\subsection{Methods of Gathering Public Input}

Researchers have developed a variety of techniques to help in gathering public input about city planning and design. Henry Sanoff, in his seminal book Visual Research Methods in Design (1991), discussed the "activity location method", which involves participants by asking them to place cards that represent various activities of city spaces on a paper map [3]. He also illustrated "knowledge of emerging environmental preservation strategies" (KEEPS), which involves the use of a sequence of sketches that characterizes change in a public space in the past, present, and future. Participants are asked to note qualities that were lost and qualities that should or should not be retained. They then share viewpoints with each other and make recommendations.

Stanley King, in his book Co-Design: A Process of Design Participation (1989), described how freehand sketching can be used to facilitate the design process of public spaces [4]. He focused on the use of on-the-spot sketching as an architectural technique with several advantages: it provides participants with an entry into the design process, promotes dialogue, and provides accurate design data afterward. Similarly, Anton Nelessen, in his book Visions for a New American Dream (1994), explained two visualization techniques-"visual preference survey" (VPS) and "hands-on model building"-that he used to promote democratic design and planning [5]. In the same vein, Wendy McClure, in her writings on Visualization Techniques for Citizen Participation (1997), described three graphic visualization strategies for engaging citizens in the process of community decision-making-citizen murals, color the map, and photo portfolios- that her team used in small towns and neighborhoods in the Pacific Northwest [6].

Likewise, Kevin Lynch pioneered the concept of "imageability of the city" by conducting survey questionnaires and utilizing maps that helped people to express their perceptions of cities and places [7]. Interestingly, Jack Nasar expanded on Lynch's imageability research by proposing the concept of "urban likeability" [8]. He conducted empirical research that posed questions and displayed photographs to learn about what people liked and disliked about specific elements of the built environment. Some scholars have used collections of postcards of a city to learn about how the popular image is constructed and how the public perceives the most popular places $[9,10]$. Remarkably, William H. Whyte conducted meticulous direct observations of public spaces and utilized camera and video techniques to record these observations [11].

Further, authors have written about the use of geographic information systems (GISes) as a visualization technique to increase public participation. They focused on how to make use of powerful and expensive GIS technology in a democracy. A significant movement called public participation geographic information systems (PPGISes) was created accordingly. It aimed to bridge the knowledge gap between GIS experts and nonexperts by engaging local people early on in the planning and design process [12].

Today, as social media is becoming increasingly popular, it offers new ways of learning about people's perceptions and interactions with the built environment through studying the photographs they record and upload. Importantly, many digital photographs contain geolocational information, such as longitudes and latitudes or street addresses. Currently, many cameras and smartphones are capable of acquiring positional information with the built-in GPS (Global Positioning System) module or based on WiFi routers or global system for mobile communications (GSM) [13]. When photographs from these devices are shared online, their locational data are also shared and can be read by other users to determine the locations where the photographs were taken. Alternatively, if photographs do not contain locational information, users can manually add geotags to pictures while uploading them to photosharing sites [14,15]. 
Ergo, the internet is an incredible source of photographic collections of places, and researchers have been attempting to exploit these imageries. For example, Snavely et al. (2008) attempted to detect spatial patterns and build mathematical models of people's use of photographs on the internet [16]. Likewise, Modsching et al. (2008) used GPS tracking data to trace the activity areas of tourists, identifying the most visited hubs and paths in the German city of Görlitz [17]. Interestingly, Girardin et al. (2008) measured tourist activities in the province of Florence, Italy, between 2005 and 2007 from photographs uploaded to Flickr.com [18].

Similarly, Shoval et al. (2011) tracked the day trips of tourists based in different hotels in Hong Kong using 3D bar diagram representations of tourist activities on the map [19]. Pettersson and Zillinger (2011) combined GPS tracking and questionnaires to gather information on tourists' experiences in relationship to their movements at sport events [20]. Ganesh (2014) studied photograph sharing over multiple social media platforms, describing the spread of photographs along links in a social network as a social cascade [21]. Capistrán (2016) studied mobile photography and social networks [22], while Kia-Keating et al. (2017) used photographs on social media to support community-based projects [23]. A recent online article titled "The Most Popular Cities on Instagram in 2017" revealed the most Instagrammed cities, indicating travelers' favorite destinations, with the following order: New York City, Moscow, London, São Paulo, Paris, Los Angeles, St. Petersburg, Jakarta, Istanbul, and Barcelona [24].

\section{Applied Methods}

In order to learn about the evaluative image of Chicago's downtown and its open spaces and architecture, this research gathered recent (2016 and 2017) locational data of photographs from major social media platforms including Twitter, Facebook, and Instagram. The total number of obtained records (indicating georeferenced and ungeoreferenced photographs) added up to 112,560. The total number of georeferenced photographs was 100,210, with the following breakdown: Instagram $(57,306)$, Facebook $(30,829)$, and Twitter $(12,075)$. Social media companies shared their data with an agreement that it would be used for the single purpose of learning about the locations of taken photographs and their collective spatial patterns. Ergo, locational data in latitude and longitude format indicated where people took their photographs that they uploaded to social media platforms.

Social media companies removed all attribute data, such as date, time, and associated comments, to ensure the privacy of the users. Consequently, there was no way for researchers to figure out when and who took what photographs and the number of photographs that individuals took. Geographic information systems visualized locational data by creating "heat maps" that displayed "socio-spatial" clusters, representing areas that were the most photographed. Participatory field visits were conducted to gather insights, and Google Maps and architectural literature were used to collect more information about these socio-spatial clusters.

Field visits to the identified clusters engaged 200 participants who were asked to photograph their favorite views that they would upload on social media. Each participant was asked to record 100 photographs. "Favorite views" were divided into two major categories, macro- and microenvironments, and participants were given the choice of the number of photographs they dedicated for each category (but totaling 100 photographs). For ensuring relative consistency, they were asked to take photographs while on grounds except for when they toured the Chicago River via the Chicago Architecture Center program. Each group of 20 participants conducted two afternoon field visits, extending from 13:00-17:00. Examples of the macroenvironment included the city skyline, major streets, and large open spaces. Examples of the microenvironment included individual buildings and skyscrapers, small vistas, plazas, open spaces, gardens, sculptures, and the like. The study did not engage participants in any written or mail survey questionnaires.

Upon collecting the photographs from their smartphones, researchers conducted short open-ended interviews with participants, inquiring about why they took these photographs and the perceptual characteristics that they liked. The questions centered on uncovering spatial relationships between 
the horizontal plane anchored by open spaces and the vertical plane established by skyscrapers. Participants were asked to offer remarks about open places and the role of tall buildings in shaping them. The collected photographs totaled 20,000. After recording interviews, researchers transcribed and analyzed contents. A keyword search of the 10 identified spatial clusters was conducted toward group comments accordingly. Additional keyword searches within each cluster were also conducted, for example using terms such as "skyscrapers", "tall buildings", and "high-rises", to learn about interviewees' views on this building typology and its spatial relationship to the city fabric. Finally, researchers summarized key findings and reported them according to the 10 identified spatial clusters. Overall, information about the discussed places came from field surveys, direct observations, architectural and urban literature, as well as the author's knowledge. These were weaved into the findings and discussion sections.

Typically, field visits took place in the afternoons of varying days of the week depending on visitors' schedules. They were preceded by morning lectures that addressed the past, present, and future developments of the city of Chicago. Lectures discussed various urban design and spatial planning perspectives and dwelled on the historic, economic, social, and political forces that shaped Chicago. They also explained the city's outstanding architecture (particularly skyscrapers), its iconic skyline, and its renowned architects and planners. Most visitors (69\%) were from China, $17 \%$ were from the Middle East, $8 \%$ were from Europe, and 6\% were from South America. All of the visits happened in the city's warmer months, May through October. Again, field visits embraced an informal structure where visitors were given the opportunity to freely express their views. Since most of them were visiting Chicago for the first time, their "first impression" about the city's planning and architecture was extremely valuable.

The survey featured a gender-balanced distribution: $48 \%$ male and $52 \%$ female. Their ages ranged from 25 to 58 . The 200 participants featured diverse professions including engineering, urban planning, architecture, administration and management, health, economic development, data sciences, education, and the like. They visited Chicago in groups of 20 members in 2018. This paper reports on views representing the majority of participants, $75 \%$ and above. Detailed statistical analysis is not the focus of this paper and could be furnished in a separate paper. All photographs were originally taken by survey participants. However, due to copyright issues, the author retook all of the photographs.

\section{Findings}

The following figures give the reader a quick glimpse of the study's key findings. Figure 1 illustrates the spatial distributions of uploaded photographs along with an aerial photograph to facilitate spatial understanding and map orientation. Figure 2 applies kernel density to spatial distribution to illustrate the 10 spatial clusters. Figure 3 shows the spatial distribution breakdown of the involved social media data, including that of Instagram, Facebook, and Twitter. Figure 4 shows the spatial distribution of photographs taken by the study participants along a kernel density overlay.

To ensure consistency, all figures retain the same geographic scale and spatial orientation: integrating the same scale bar in maps helps in this regard. Each dot in every figure represents the locations of 10 photographs, also for the sake of consistency. Dots that fall in Lake Michigan represent photographs that were taken by people riding private and public boats. The arc-shaped dot cluster placed over the lake represents a public boat path that transports people from the Museum Campus in the south to Navy Pier in the north and vice versa. These dots were exclusive to social media data. Survey participants' data did not show photographs taken on this route. 

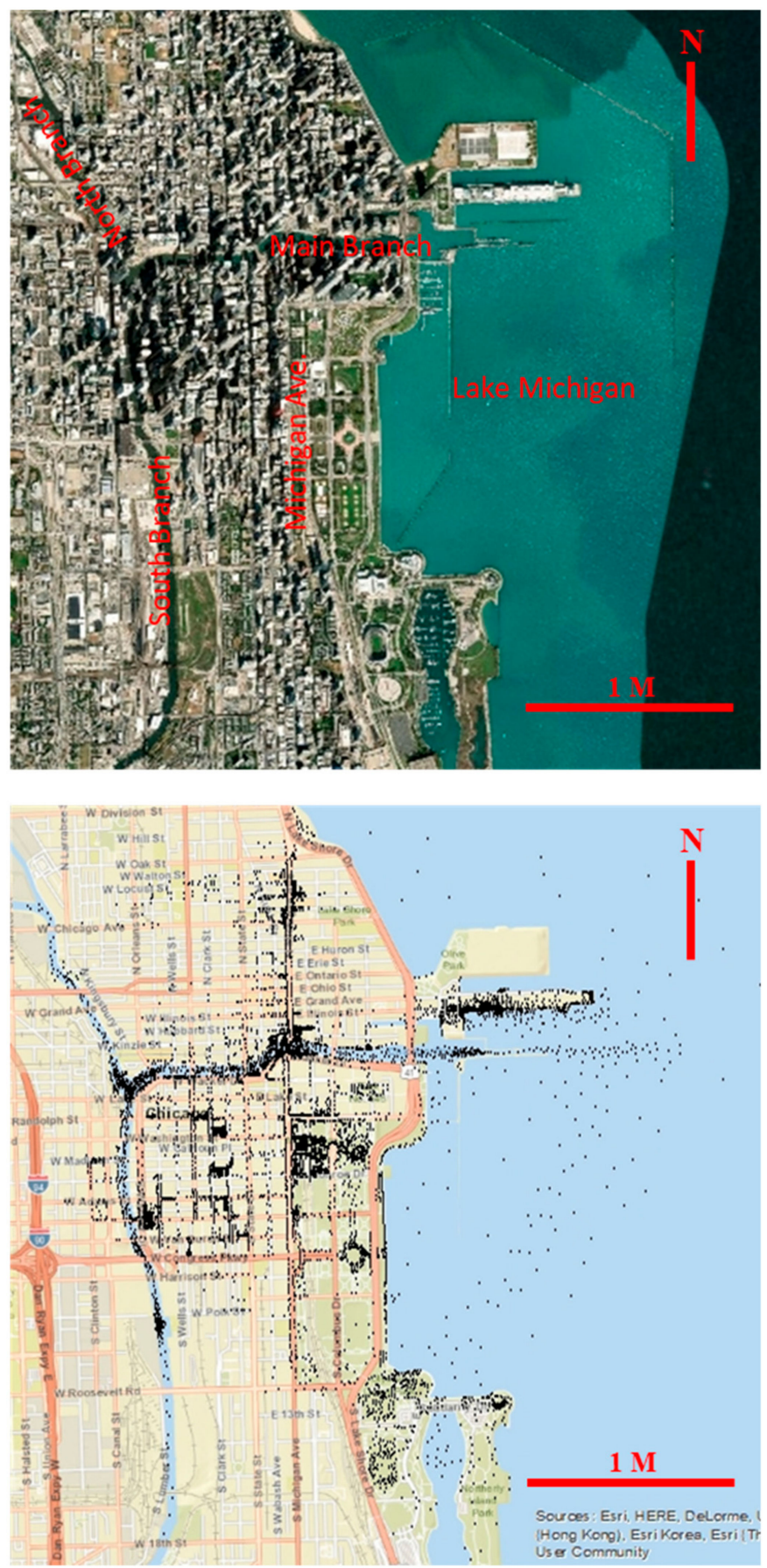

Figure 1. Top map shows an aerial view of downtown Chicago. Bottom map shows locations of uploaded photographs to social media sites with a street map in the background. 


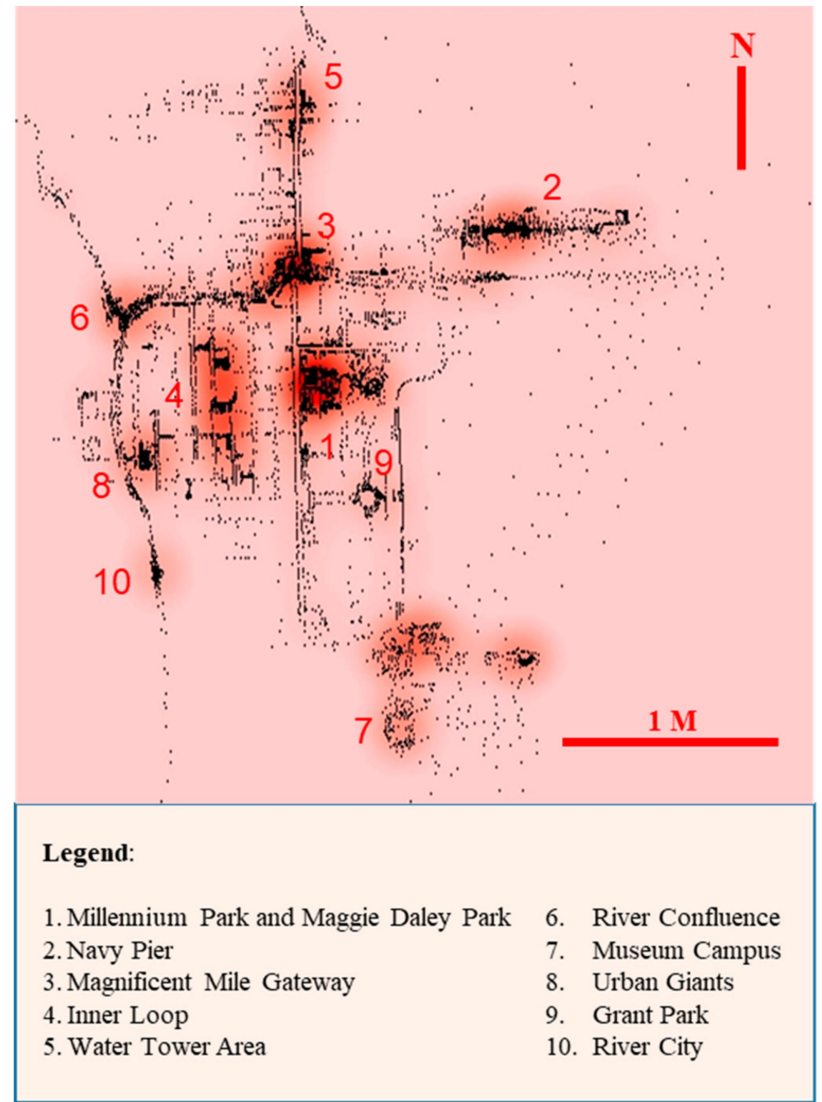

Figure 2. Map shows spatial distribution of uploaded photographs while applying the kernel density method, illustrating the identified 10 socio-spatial clusters. Color variation indicates the intensity of the taken photographs: the heavier color indicates a greater number of registered photographs, and the lighter color indicates a lesser number.

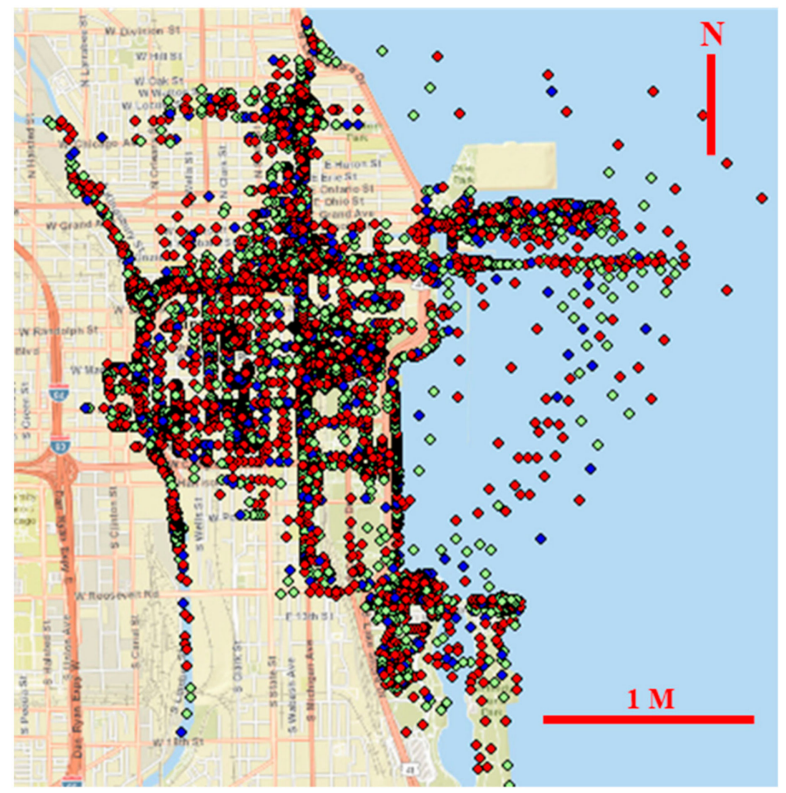

Figure 3. Map shows the spatial distribution of social media photographs: red dots = Instagram, green dots $=$ Facebook, and blue dots $=$ Twitter. Note that that the dominant color is red, followed by green and blue, proportionally representing the number of taken photographs on different social media platforms. 


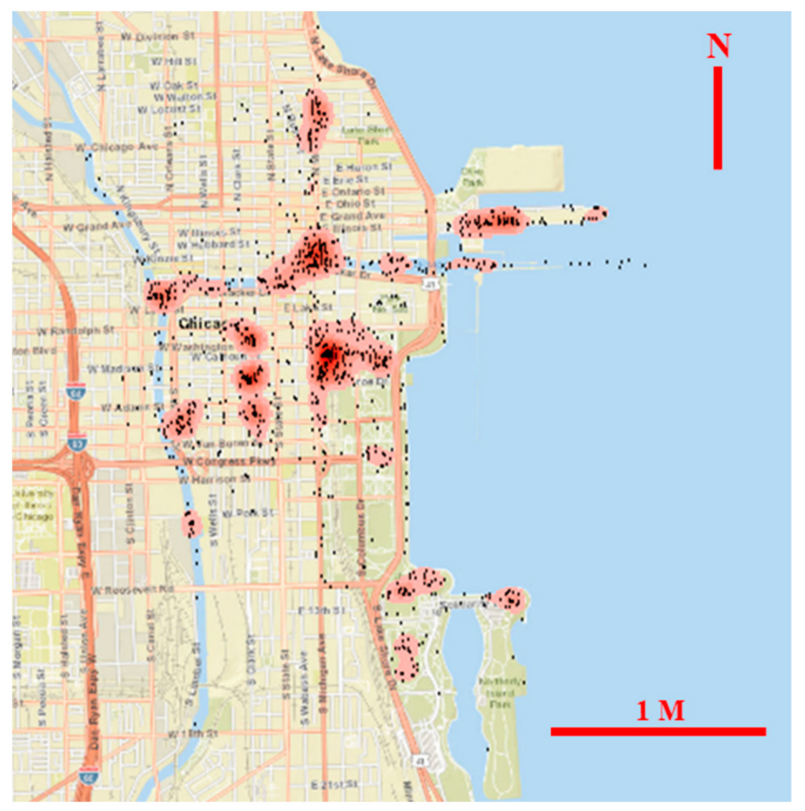

Figure 4. Map shows the spatial distribution of photographs taken by study participants along a kernel density overlay. Dots placed over the Chicago River and Lake Michigan represent locations of photographs taken by participants while they were on a boat tour. Color variation indicates the intensity of the taken photographs: the heavier color indicates a greater number of registered photographs, and the lighter color indicates a lesser number.

The spatial distribution of social media photographs revealed 10 major clusters as follows: (1) Millennium Park and Maggie Daley Park, (2) Navy Pier, (3) the Magnificent Mile Gateway, (4) the Inner Loop, (5) the Water Tower Area, (6) the River Confluence, (7) the Museum Campus, (8) "Urban Giants", (9) Grant Park, and (10) River City (Figure 2). Importantly, participant survey results, illustrated in Figure 4, echoed these clusters. In the heart of the Loop community, several public plazas (e.g., Daley Plaza, Chase Plaza, Federal Plaza, and 311 South Wacker Plaza) along Millennium Park and Maggie Daley Park animate the Loop. In addition, the Chicago Riverwalk area activates the northern edge of the Loop, while the intersection of the river with Michigan Avenue features an agglomeration of activities and buildings that create a remarkable gateway to the Magnificent Mile. At the eastern end, Navy Pier offers an entertaining space, and westward River City provides an intriguing visual terminus to the river tour. Further, toward the southern end, the Museum Campus grants visitors unique experiences due to outstanding exhibits. Externally, the campus location offers spectacular vistas to the city's iconic skyline. Similarly, the nearby Lakeshore Drive walkway and bikeway also offer splendid views of Lake Michigan and the city skyline.

In terms of spatial connectivity, all of these spatial clusters are within a couple of miles, making them easily accessible on foot or by bike, Segway, mass transit (train and bus), or private automobile. Plazas within the Loop are just a block or a couple of blocks apart. Interestingly, Millennium Park and Maggie Daley Park feature great connectivity, as they are within 10-min walking distance from the Loop and the Chicago Riverwalk, $15 \mathrm{~min}$ from the Magnificent Mile, and $20 \mathrm{~min}$ from Navy Pier and Museum Campus. Notably, the Chicago Riverwalk connects Navy Pier with the Loop, while the Lakeshore walkway connects the Campus Museum with the Loop. Finally, the Magnificent Mile connects the upper end of the downtown with the Loop.

This section reports about findings according to the following structure. It groups participants verbal responses based on the identified 10 socio-spatial clusters. The discussion of each cluster starts by providing background information on the examined space, basic descriptions of the major features and characteristics, and an illustration of planning and design principles. The subsequent paragraphs report about participants' views on the city public spaces and architecture. Due to the space limitations 
of a single paper, the reporting is reduced to key findings. As mentioned earlier, the paper reports about issues that at least $75 \%$ of participants agreed about. Other findings and controversial issues could be furnished in a future paper.

\subsection{Millennium Park and Maggie Daley Park}

Due to their spatial proximity and design affinity, participants viewed these two parks and the British Petroleum (BP) Pedestrian Bridge that connects them as a "unified" cluster. The Millennium Park is a 24.5 -acre (10 hectares) public space located in the Loop Community. The spatial layout of the park follows an "imageable urban room" structure, a concept that Daniel Burnham and Edward Bennett initially promoted for their design of Grant Park in 1909. As such, the park contains 12 major "urban rooms", including the AT\&T Plaza and Cloud Gate Sculpture, the Crown Fountains, the Jay Pritzker Pavilion, the BP Pedestrian Bridge, Lurie Gardens, the Boeing Galleries, the Chase Promenade, the Exelon Pavilions, the Harris Theater for Music and Dance, the McCormick Tribune Plaza and Ice Rink, the McDonald's Cycle Center, and the Wrigley Square and Millennium Monument.

The study's participants liked the park's great variety of entertaining elements, including attractive open spaces, spectacular public art pieces, iconic pavilions, splendid gardens, and seasonal art displays. They also liked the small "urban room" concept and how the park's relatively intimate places profoundly engage all of the senses and consequently compensate for the highly developed downtown area. In addition, these distinct spaces convey a strong design identity to the park.

The most photographed object in Millennium Park is the Cloud Gate sculpture, which Chicagoans have nicknamed "the Bean". Both social media data and participant surveys underlined this sculpture. While social media illustrated a large number of dots around the sculpture, participants' photographs showed the Bean from various perspectives and even latitudes, i.e., some participants walked and crawled underneath the Bean to photograph it. Participants admired the sculpture because it coalesces the city's various parts, including public spaces, greenery, trees, shrubs, skyscrapers, people, the sky, and clouds. It also mirrors visitors' movements and gestures. Further, it appears differently when viewed from different locations: it looks like a sphere or bean and whatever is in between. Interestingly, the curvilinear geometry of the sculpture contrasts well with skyscrapers' straight edges in the background. Skyscrapers' linear arrangement also promotes a sense of enclosure and complements the spaciousness of the plaza surrounding the sculpture (Figure 5).

As is the case with the Cloud Gate sculpture, the nearby Crown Fountains offer visitors an interactive experience. While the Cloud Gate makes people reflect on the city's dynamism and visitors' gestures and movements, the Crown Fountains engage visitors with a water splash exhilarating experience. The Crown Fountains Plaza consists of a pair of 15-m (50-ft) high glass-brick towers placed $50 \mathrm{~m}(165 \mathrm{ft})$ apart in a plaza covered with black Zimbabwe granite. At a rate of 11,500 gallons per hour, water spews from the towers' tops and splashes against the ground near large crowds of people who flock to this installation in the hot summer months. What makes these fountains particularly interactive is a set of LED (Light-Emitting Diode) screens placed on the exterior, which displays videos of exotic landscaping and the faces of 1000 Chicagoans, representing a demographic cross-section of the Chicago region. Direct observations and the field survey indicated that these two spaces (Cloud Gate Plaza and Crown Fountains Plaza) are particularly used after dusk. Due to their spatial closeness to busy and vibrant Michigan Avenue, participants felt safe in these spaces even after sunset.

Other attractive features of Millennium Park include Lurie Garden. Located near the southern edge of the park, Lurie Garden is a spectacular five-acre "prairie oasis". The study participants liked the garden immensely for offering a respite from urban life and engaging them in an immersive nature experience that allows for a temporary "mental" escape from the nearby "urban jungle", characterized by busy streets as well as massive steel and glass and concrete structures. The garden hosts indigenous vegetation. Its organic and natural appearance also offers a complementing contrast to the orderly building environment dominated by skyscrapers (Figure 6). 

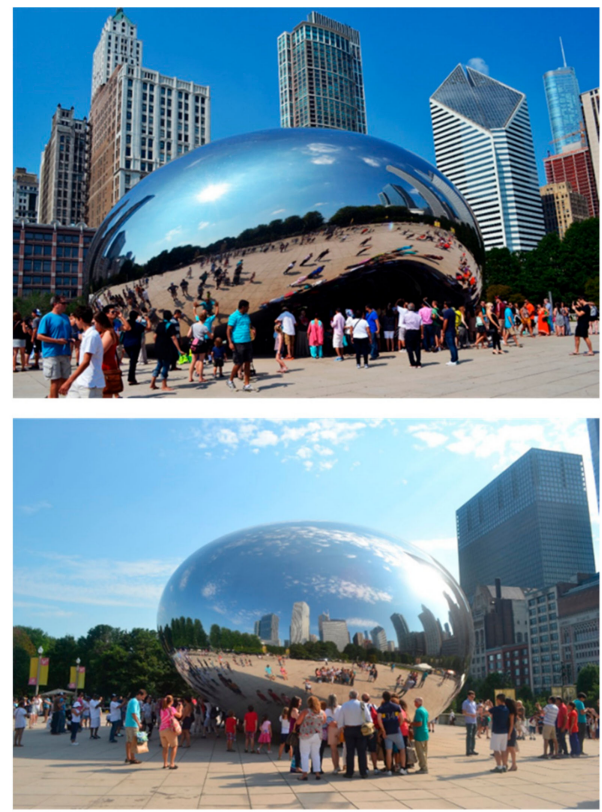

Figure 5. According to social media and participant surveys, the most photographed object in Millennium Park is the Cloud Gate sculpture. Participants admired the sculpture because it coalesces the city's various parts, including public spaces, greenery, trees, shrubs, skyscrapers, people, the sky, and clouds. It also mirrors visitors' movements and gestures. Further, it appears differently when viewed from different locations: it looks like a sphere or a bean and whatever is in between (compare top and bottom photographs). Interestingly, the curvilinear geometry of the Bean contrasts well with the straight edges of skyscrapers in the background. Skyscrapers' linear arrangement also promotes a sense of enclosure and complements the spaciousness of the plaza surrounding the Bean.
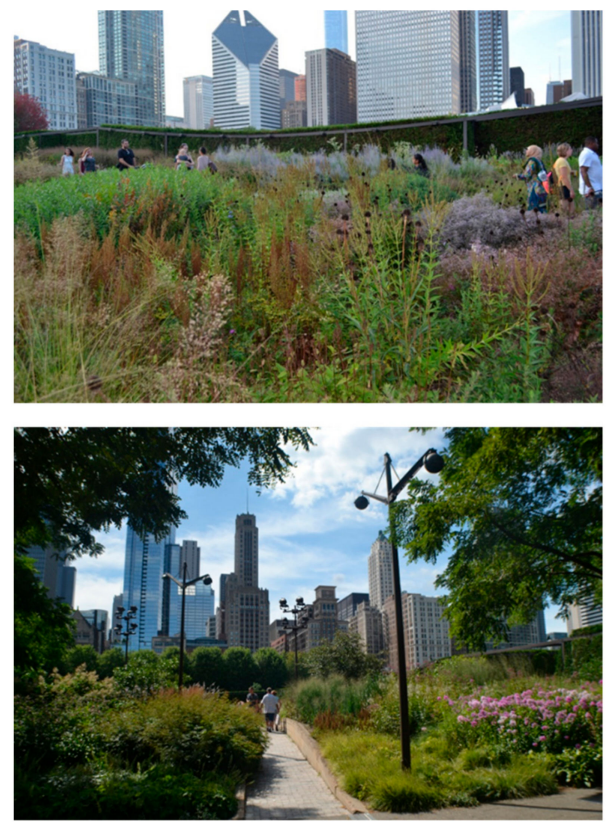

Figure 6. Among the most attractive features in Millennium Park is Lurie Garden. Located near the southern edge of the park, Lurie Garden is a spectacular five-acre "prairie oasis". The study participants liked the garden immensely for offering a respite from urban life and engaging them in an immersive nature experience that allows for a temporary "mental" escape from the nearby "urban jungle". The garden hosts indigenous vegetation. Its organic and natural appearance also evokes a complementing contrast with the orderly building environment dominated by skyscrapers. 
Maggie Daley Park (MDP) is located immediately east of Millennium Park. The layout of this graceful park features a winding spine that cuts diagonally through the space, dividing the park into two parts: a southeast section that contains the Play Garden and a northwest section that contains the Rock Climbing Walls and the J.B. and M.K. Pritzker Family Ice Skating Ribbon. The study participants liked the great variety of play spaces, which were designed mainly for children. They also expressed appreciation of the park's curvilinear and intricate topography, which offers a complimenting contrast with the city's flat and gridded character. They noted how the tall buildings promote a sense of enclosure around the park (Figure 7).
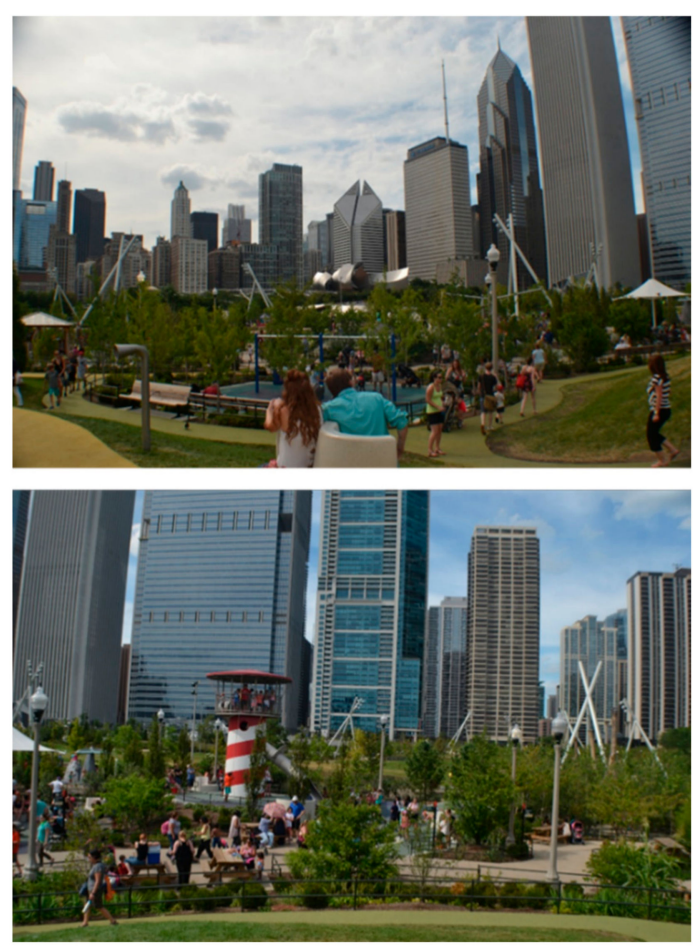

Figure 7. Maggie Daley Park. Study participants appreciated the 20-acre park for providing spaces and activities that cater to all ages to enjoy, relax, and play in. They also appreciated the park's hills, valleys, and vistas that animate the place and shield visitors from the sun, wind, and traffic noise. Further, the park's curvilinear and intricate topography offers a complimenting contrast to the city's flat and gridded character. In addition, its relentlessly heterogeneous space complements that of Grant Park's formal layout.

\subsection{Navy Pier}

Navy Pier is a 3000-foot-long pier that was built in 1916. It is one of a pair proposed for the lakefront in Daniel Burnham's 1909 Plan of Chicago [25]. The study participants liked the great variety of shops, amusement, and recreational areas contained in the 50-acre pier. They also liked the Crystal Gardens, a two-story spaceframe that houses a children's museum and a botanical garden as well as the Ferris Wheel, a giant device echoing the original that dominated the 1893 World's Columbian Exposition. Participants enjoyed taking photographs of Navy Pier while having the city skyline in the background (Figure 8). 

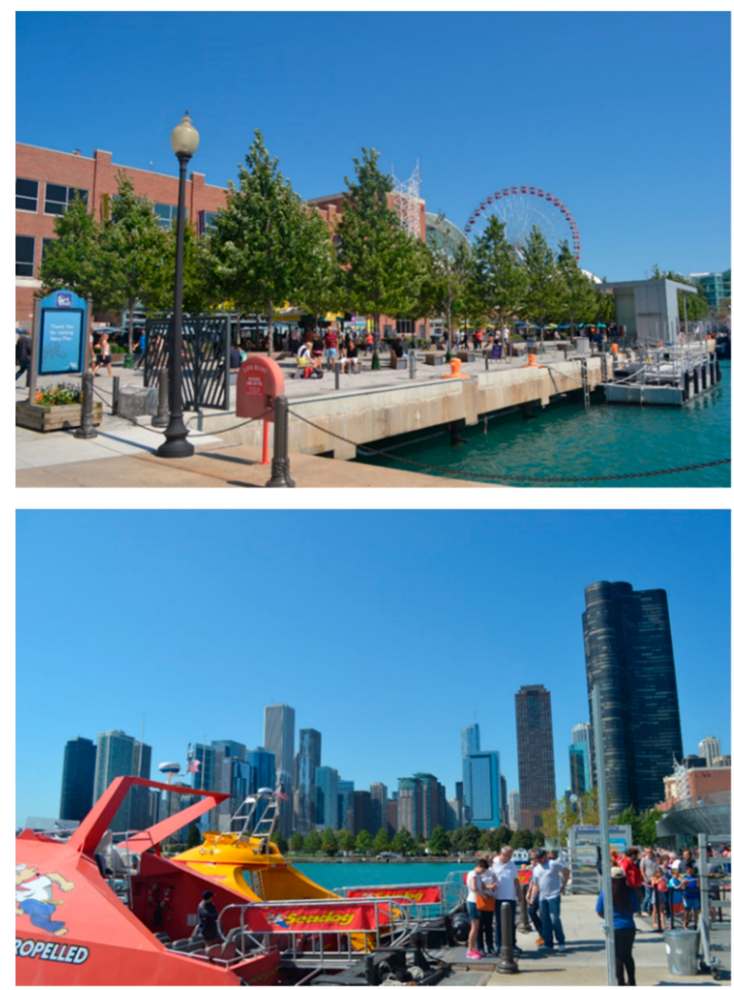

Figure 8. Navy Pier is a 3000-foot-long pier entertainment district. Study participants liked the great variety of shops, amusement, and recreational areas supplied by this 50 -acre pier. They also enjoyed taking photographs of Navy Pier while having the city skyline in the background.

\subsection{The Magnificent Mile Gateway}

A stunning agglomeration of historic skyscrapers along the DuSable Bridge creates a Grand Gateway to the Magnificent Mile. These are the Wrigley Building, Tribune Tower, LondonHouse Chicago, and 333 North Michigan Avenue. This spectacular cluster of skyscrapers has helped to spatially define one of America's most dramatic urban places [26]. What participants liked in particular was that the design of these buildings consistently follows a classical architectural style. Indeed, the cluster is reminiscent of buildings of the "White City" at the World's Columbian Exposition of $1893[27,28]$. The study participants appreciated the fact that all of these buildings have consistently distinctive bases, shafts, and tops, contributing to the urban design coherence featured in this area. Additional buildings, such as the Equitable Building (1965) and the more recent Trump Tower (2009), have further strengthened this spatial urban node. The 1920 DuSable Bridge centers the place and adds beauty, significance, and drama. In particular, participants liked the way a cluster of historic tall buildings creates a remarkable gateway to North Michigan Avenue. Plazas and open spaces agglomerate near the southern end of the Magnificent Mile (Figure 9). 

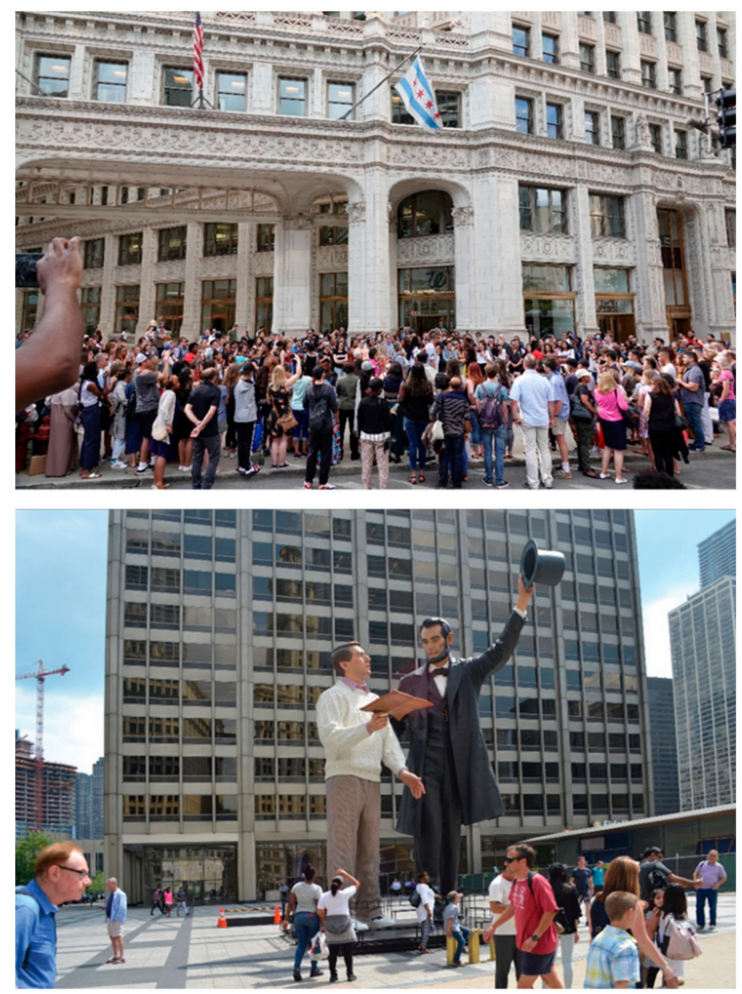

Figure 9. Plazas and open spaces cluster near the southern end of the Magnificent Mile. The top photograph shows the Wrigley Building's plaza, and the bottom photograph displays the Pioneer Court anchored by temporary public sculptures, in this case the "Return Visit" sculpture. Created by Seward Johnson, it depicts a giant Abraham Lincoln, the 16th U.S. president, standing next to a "common man", or a white man in a cable-knit sweater and corduroy pants. Study participants appreciated these spacious places amid the busy and crowded downtown.

\subsection{Inner Loop}

Within the Inner Chicago Loop (defined as the area bordered by Chicago River northward and westward, Michigan Avenue eastward, and Roosevelt Road southward), the study identified sub-socio-spatial clusters that are created by several public plazas. These plazas function as "lungs" in the crowded Loop. Their horizontal nature balances the Loop's verticality (established by skyscrapers). In addition, the voids they create within the Loop canvas allow people to gather and enliven it with a variety of social and political activities. Overall, people use the Loop's plazas mainly around lunchtime. Among the major plazas in this area are Daley Plaza, Chase Plaza, and Federal Plaza, discussed respectively below.

\subsubsection{Daley Plaza}

A remarkable spatial node is located near the Loop's civic epicenter. It is created by the clustering of important tall buildings, including the Richard J. Daley Center, City Hall, the James R. Thompson Center, and Grant Thornton Tower. The study participants expressed appreciation of the diverse architectural styles that these buildings represent, including classical, international, late modernism, and postmodernism. Most importantly, they liked that Daley Plaza offers a major outdoor urban space that attracts a good part of the city's residents and visitors. Enriched by programmed social and cultural activities, Daley Plaza is a grand public space, performing as the heart and soul of the Loop. 


\subsubsection{Chase Plaza}

About two blocks south of Daley Plaza, the study identified another sub-socio-spatial cluster that comprises the Chase Center, flanked by the Inland Steel Building, One South Dearborn East, and 55 West Monroe (the Xerox Building). These buildings center on Chase Plaza. The study participants liked a number of attractive elements of the plaza, including its spacious sunken space, large fountain, clock tower, public art, and lush landscaping. They explained that Chase Plaza forms the Loop Oasis.

\subsubsection{Federal Plaza}

About two blocks south of Chase Plaza, there is another intriguing socio-spatial cluster created mainly by the Chicago Federal Center Complex, Monadnock Building, and Marquette Building. Like the discussed earlier clusters, this spatial node offers a splendid contrast of distinct architectural styles. Participants liked how the historic, heavy masonry Monadnock Building contrasts with the nearby modernist Miesian architecture of the Federal Complex. Importantly, the spacious plaza that centers the complex is a place for numerous civic activities, including social, political, cultural, and entertainment activities, that draw masses of people who enliven the space. Overall, the participants felt that these plazas offer respite from the stressful, busy Loop (Figure 10).
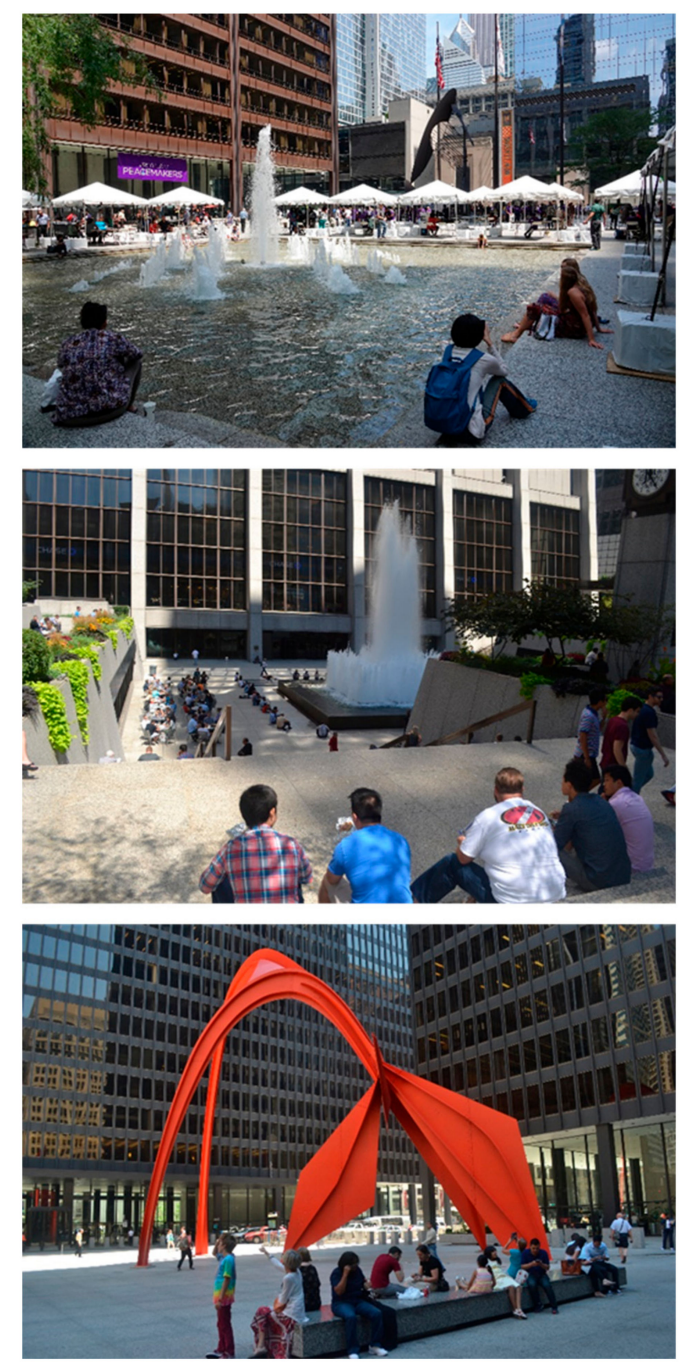

Figure 10. Inner Loop: Daley Plaza, Chase Plaza, and Federal Plaza, respectively. Participants felt that these plazas offer respite from the stressful, busy Loop. 


\subsection{Water Tower Area}

Along the Magnificent Mile, a prime cluster of remarkable buildings and plazas is located between the Chicago Water Tower and the One Magnificent Mile Building. Vertical malls draw in masses of visitors and ignite socioeconomic activities in this place. The study participants liked how this spatial node is characterized by a blend of historic, modern, and ultramodern buildings, which certainly make this cluster one of the unique places in the city. In addition, open spaces and plazas humanize the place, and extensive landscaping and seasonal public art make it even more attractive and enticing. Among the key buildings and structures of this cluster are the Chicago Water Tower, Water Tower Place, the Park Tower, 875 North Michigan Avenue (popularly known as the John Hancock Center), 900 North Michigan Avenue, the Palmolive Building, and One Magnificent Mile. Among the most popular plazas is the John Hancock Plaza (Figure 11).
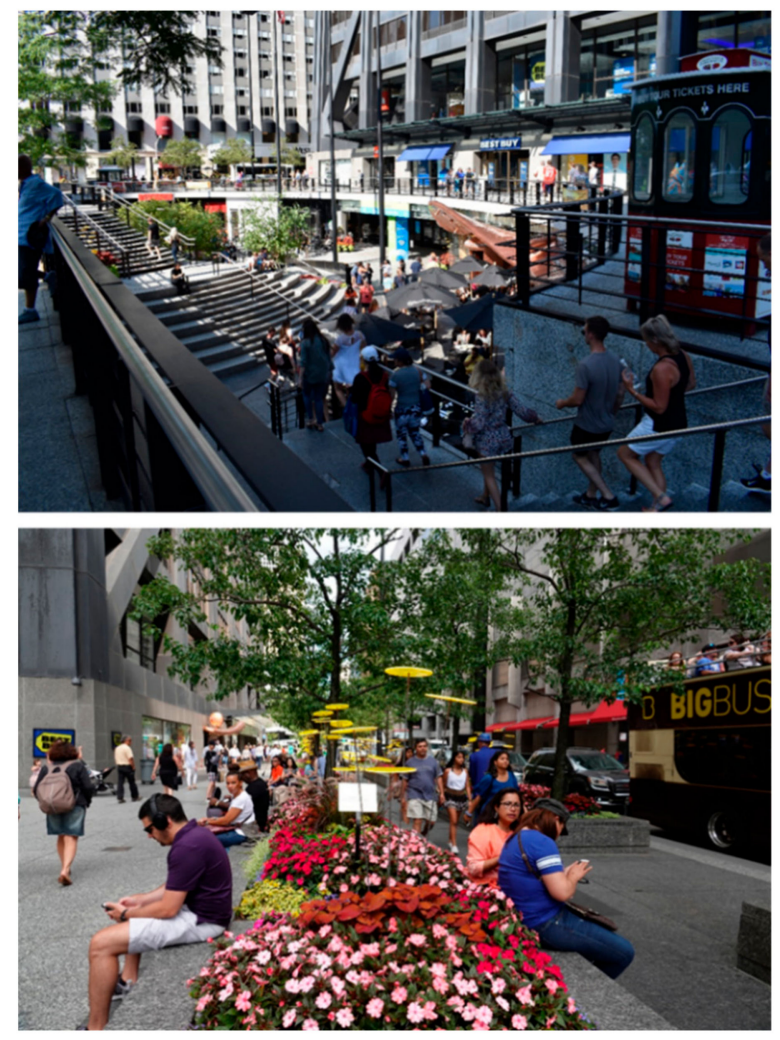

Figure 11. A cluster of plazas near the northern end of the Magnificent Mile offers pedestrians relaxing places. Study participants liked the John Hancock Plaza, shown in the photographs.

\subsection{River Confluence}

The Chicago River runs through a canyon of spectacular skyscrapers. What is particularly interesting is that the river's three branches (Main, North, and South) meander and curve slightly, provoking a dynamic visual experience of this canyon. One of the most remarkable clusters of skyscrapers, however, occurs at the Chicago River confluence, where the river's three branches meet. Among these buildings are 333 West Wacker Drive, 225 West Wacker Drive, 191 North Wacker Drive, River Point, 150 North Riverside, Boeing International Headquarters, the Residences at Riverbend, Merchandise Mart, and Wolf Point West. While each building is an architectural masterpiece, their collective presence evokes a special visual effect. The contrast of the river's horizontality and the skyscrapers' verticality is remarkable. In addition, water reflection improves the individual and collective presence of these skyscrapers. Indeed, skyscrapers here create a dramatic spatial node (Figure 12). When Wolf Point East (under construction) and the proposed Wolf Point South are built, these towers will surely reinforce the imageability of this spatial node and redefine the river's skyline. 
Interesting, Boeing International Headquarters marks the beginning of the South Branch, and the Residences at Riverbend marks the beginning of the North Branch.
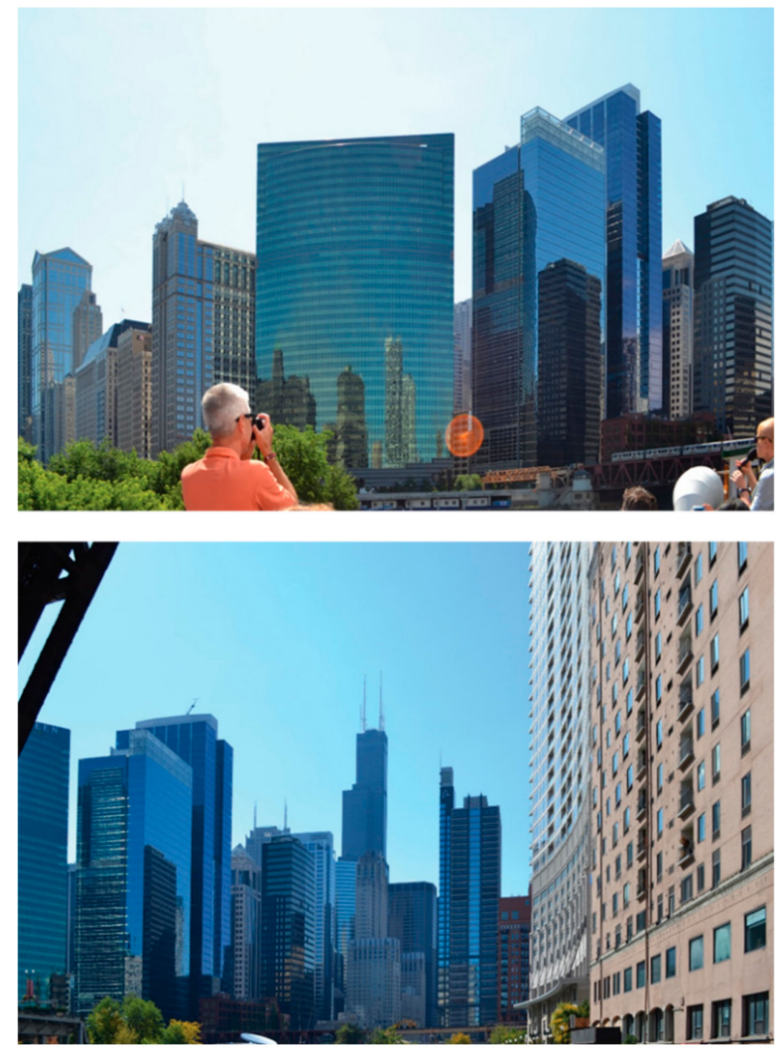

Figure 12. One of the most spectacular spots along the Chicago River is the river confluence where its three branches meet. As the boat turns, riders stand and take photographs of tall buildings surrounding this area.

\subsection{Museum Campus}

On Chicago's lakefront, toward the south end of Grant Park, a great agglomeration of museums and other public facilities is placed. Still just a portion of Lake Michigan in 1910, it was filled with land and developed in accordance with the Burnham Plan of 1909. The campus houses the Field Museum, Soldier Field, Shedd Aquarium, and Adler Planetarium. The spaciousness of Grant Park creates a healthy distance between this cluster and the Loop, which allows visitors to appreciate the city's iconic skyline. From this location, participants often place the city skyline in the background of their photographs (Figure 13). 


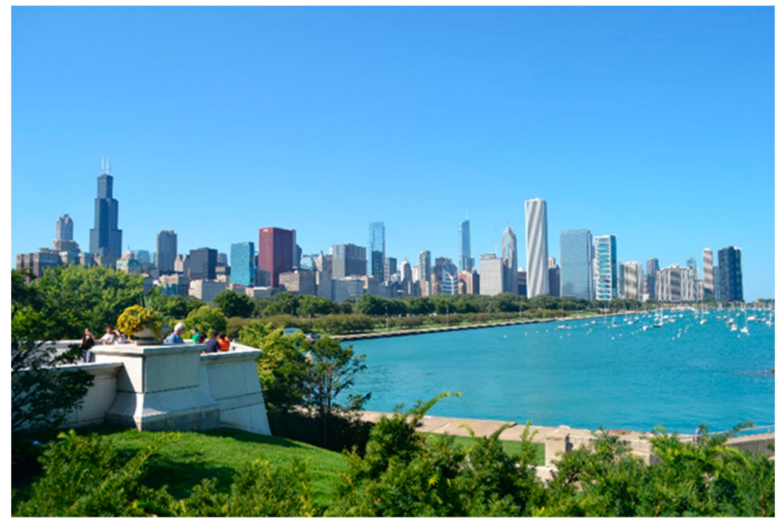

Figure 13. In addition to offering a variety of indoor exhibits, the Museum Campus area provides excellent vistas on the city's remarkable skyline.

\subsection{Urban Giants}

On the western side of the Loop, near the South Branch of the Chicago River, an outstanding cluster of skyscrapers along Wacker Drive creates a unique space, "the city's spatial signature", as participants indicated. There, one finds "Urban Giants", including Willis Tower (Chicago's tallest building), 311 South Wacker Drive, and Franklin Center. The 311 South Walker Plaza in conjunction with the area near the south entrance of the Willis Tower is at the epicenter of this cluster. Participants were impressed by the boulevard's spaciousness and the role of tall buildings in presenting it as a strong path and powerful edge to the Loop (Figure 14).

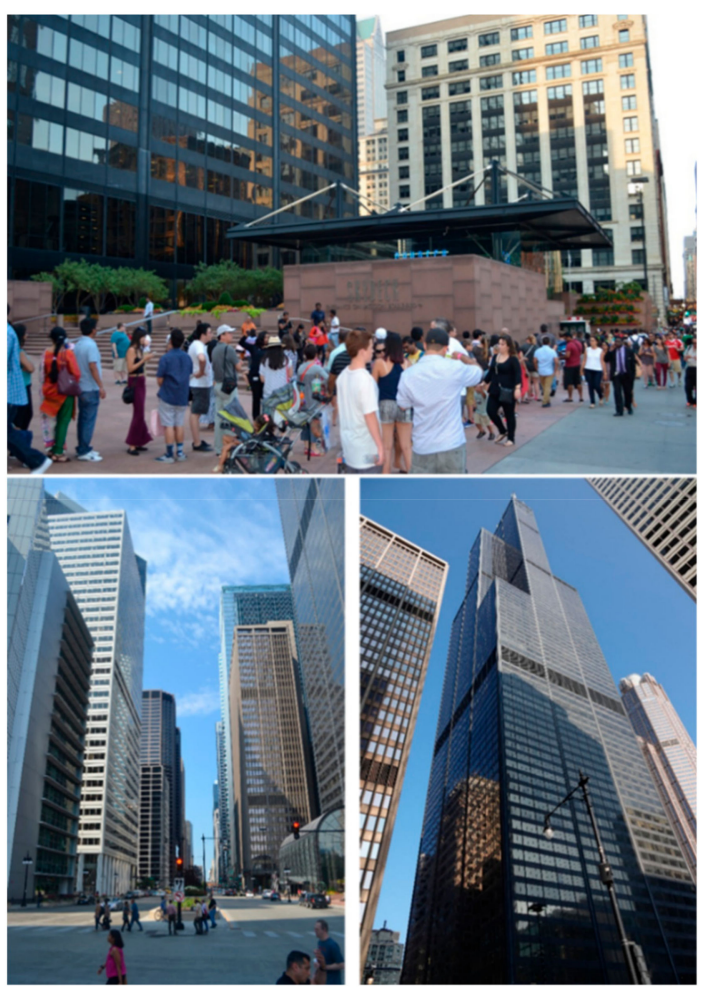

Figure 14. "Giant" skyscrapers line up alongside the Wacker Drive corridor. Among these skyscrapers is the Willis Tower, Chicago's tallest building. Interestingly, plazas around the building's base enliven the area. People entertain and wait in line to visit the observation deck, "Skydeck", located on the 103rd floor. 


\subsection{Grant Park}

With an area of 319 acres, it is the largest urban park in the Loop community, making it a major "breathing" space in downtown Chicago. The north side of the park was remodeled from 1998 to 2014, creating Millennium Park and Maggie Daley Park, which were explained in Section 3.1. Earlier, the 57-acre Museum Campus was added to Grant Park's southeastern end, which was explained in Section 3.7. Grant Park contains performance venues, gardens, artwork, sports, and harbor facilities. It hosts public gatherings and several large annual events. Interestingly, the park's most remarkable features are the Buckingham Fountain and the Art Institute of Chicago.

Indeed, the Buckingham Fountain's central location, its large size, and its magnificent design make it a special feature that contributes to the imageability of the park and the city at large. Built in 1927, the fountain boasts being one of the largest in the world. It features the iconic art deco style and four seahorses surrounding it, representing Lake Michigan's four bordering states. From 8:00 to 23:00, the fountain bursts to life hourly, shooting 15,000 gallons of water through nearly 200 nozzles every minute, thereby fashioning a striking display. After dusk, the water show is accompanied by lights. The fountain was a donation from the Buckingham family [29]. Interestingly, the study participants often photographed the Buckingham Fountain with the city skyline in the background (Figure 15). It is worth noting that participants' photographs were taken during daytime and hence did not illustrate the visual effect of the fountain's sophisticated lighting system, which is often presented by photographs found in architectural books and online sources.

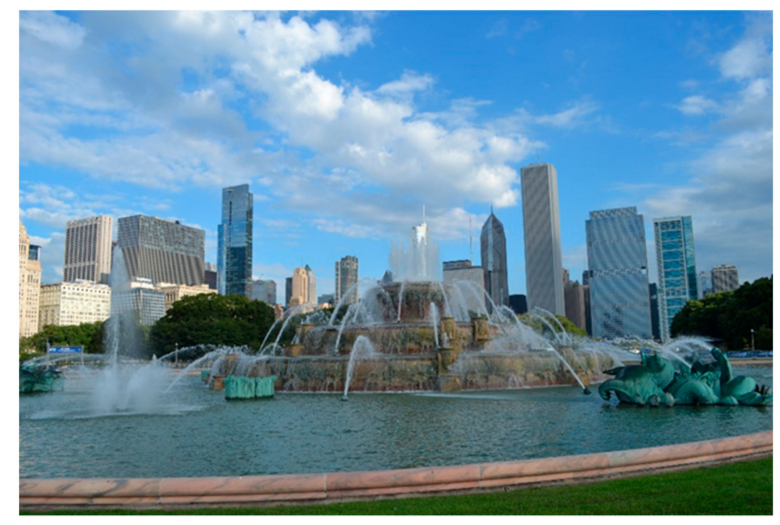

Figure 15. Centering Grant Park is the Buckingham Fountain. Built in 1927 and featuring an iconic art deco style, the fountain boasts being one of the largest in the world. Interestingly, study participants often photographed the Buckingham Fountain with the city skyline in the background.

\subsection{River City}

River City is a mixed-use complex that was designed by Bertrand Goldberg and completed in 1986. In addition to its outstanding organic character, the complex enjoys a prominent site along the edge created by the Chicago River's South Branch. What also signifies this complex is that it is located where the Chicago River's Architectural Boat Tour reverses direction. At this point, the boat stops for a few minutes to let riders take photographs of the surrounding, including the River City complex and the city's iconic skyline in the background (Figure 16). 

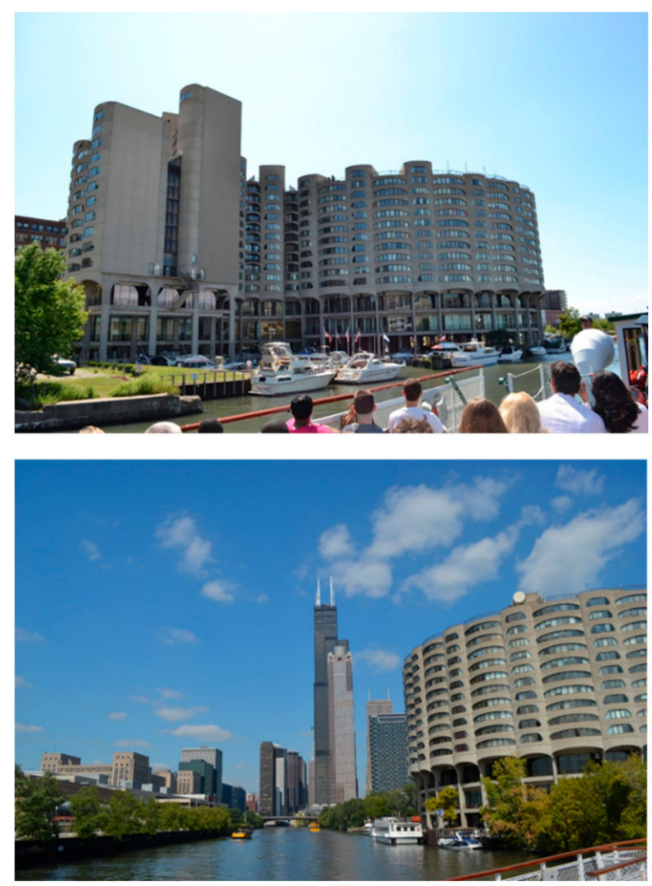

Figure 16. At the southern end of the boat tour, study participants admired the River City complex (top). They also liked the city skyline centered by the Willis Tower, the city's tallest building (bottom).

\section{Discussion}

With a focus on Downtown Chicago, this study utilized social media data and field surveys to reveal the most popular "agglomeration" of places and skyscrapers. Geographic information systems were utilized to visualize their locations and the intensity of use and popularity. That is, locational data of photographs taken by the public allowed for seeing Chicago as a collage of socio-spatial clusters with a defined hierarchy. Direct observations and architecture literature further informed on these clusters. Collectively, the employed methods provided a lens to understanding what people admire and appreciate. It facilitated a new form of urban analysis while revealing the pulse of the city.

Individual landmark buildings and major public spaces in the city of Chicago are already known. However, this study enabled the delineation of spatial clusters of landmark buildings and public places, amenities, parks, and museums, thereby offering a new read on city life. Certainly, their collective iconic presence complements their individual beauty. Undoubtedly, these spaces are essential to the sustainability of the city, and social media is fueling their significance. That is, the more people upload photographs of places, the more popular they become in the minds of people, and consequently, more people visit them.

Ergo, there is a circular relationship, or a feedback loop system, between social media and urban places. That is, by sharing photographs online, photographed places become increasingly popular, encouraging more people to visit them, who then take more photographs and share them again on social media platforms. That is, social media has the potential to advertise and popularize places and hence ignite and exploit the "social energy" of the city. This mutually supportive relationship creates a feedback loop system that planners and decision-makers should tap into (Figure 17).

The findings of this study highlight the significant impact of Millennium Park and Maggie Daley Park on the city's downtown. First, these two parks are among the most popular, most photographed places. Second, their location is very strategic, as they are close to the downtown action, and consequently, they virtually connect the Inner Loop with South Michigan Avenue, the Magnificent Mile, and the Chicago Riverwalk. These parks create a spatial "bubble", as seen in the heat maps, also connecting the Grand Gateway of the Magnificent Mile with the Inner Loop. In other words, Millennium Park and Maggie Daley Park have become the center of gravity for the entire city. 


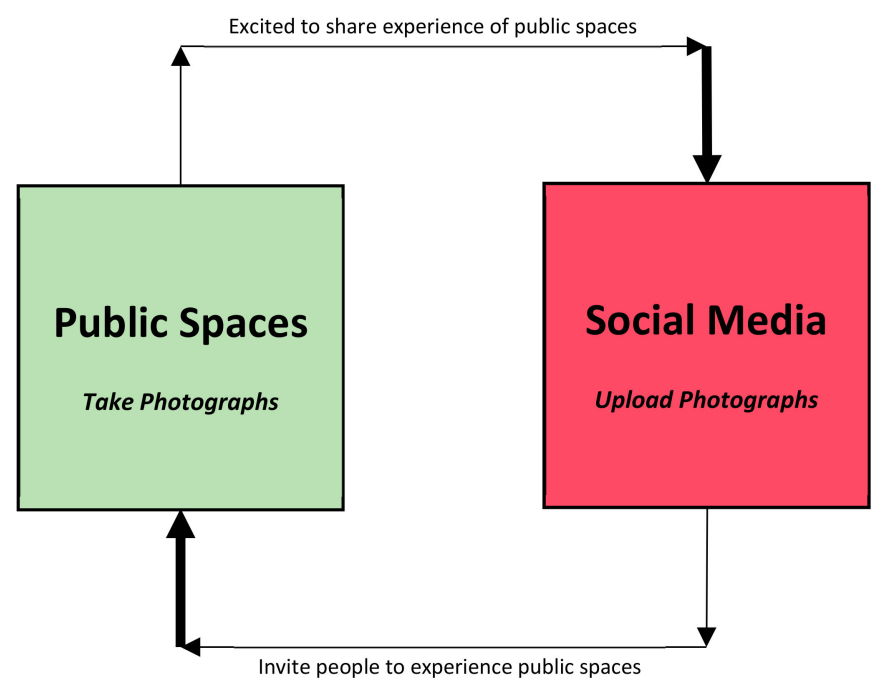

Figure 17. Social media and public spaces: feedback loop system. As people visit public spaces, many upload their photographs on social media websites. These shared photographs advertise, encourage, and invite other people to visit these spaces. When more people visit and upload photographs, social media invites more people to visit these spaces, making them more popular.

One of the most notable elements of Millennium Park is the wonderful transition one experiences from being immersed in skyscrapers to walking into an open green space with lush landscaping, vendors, music, and, most importantly, people. The park is accessible to the public and is free of charge. Aesthetically, the major part of the city's skyline (two intersecting rows of spectacular skyscrapers creating an L-shaped edge) hugs the park and functions as a fantastic backdrop. Furthermore, the park's public art pieces, such as the Crown Fountains and the Cloud Gate, are overscaled in order to provide a spatial transition between the soaring skyscrapers nearby and the "flat" park they reside in [30].

Interestingly, Maggie Daley Park's curvilinear and intricate topography contrasts well with the city's flat and gridded character. In a similar manner, the park's cascade of heterogeneous spaces acts as a complement to Grant Park's formal layout. The organic nature of the park also complements the rigid appearance of the glass, steel, and concrete skyscrapers that surround it, helping to mitigate the overwhelming verticality of these tall structures. The park humanizes the space, and the city's skyline works as a spectacular backdrop [31].

The findings of this study also agree with William $\mathrm{H}$. Whyte's research, which suggested that there is a mutually supportive relationship between high-rise buildings and plazas and open spaces. That is, open spaces provide a "spatial break" for people to gather, while high-rise buildings supply the needed density of people to make good use of public places. People who live, work, and visit a high-rise city may feel claustrophobic, and open spaces become a place to relax, socialize, and take photographs.

In addition to identifying important socio-spatial clusters in the city, this study highlights the important role of the Chicago River boat tours and the Chicago Riverwalk. There are masses of photographs that are taken along the river because of the tours and Riverwalk. Indeed, the path goes through a spectacular canyon of skyscrapers and beautiful places provided recently by the Riverwalk. A special place, as indicated earlier, is the River Confluence, where the three branches of the river meet: Main, North, and South. This place has also been photographed extensively.

In the same manner, Michigan Avenue's significance is highlighted through the stream of photographs taken along it. There is a major spatial "bubble" that occurs at the beginning of the Magnificent Mile, where Michigan Avenue intersects with the Chicago River. At that spot, a cluster of outstanding skyscrapers (old and new), plazas (Wrigley Plaza and Pioneer Court), and special urban artifacts (e.g., the DuSable Bridge or Michigan Avenue Bridge) make this spot very special. Another "bubble" occurs at the upper end, where important skyscrapers and historic structures cluster. 
The idea that the whole can be greater than the sum of its parts is particularly apparent in this study. While each building makes a unique contribution, Chicago's great skyline is composed of a concert of iconic buildings. Each one is a new piece of this evolving city, enhancing the urban collage and contributing to the urban design experience. This collective work of art forms an elegant record of the city's innovation roots and artistic development. Many of the newly constructed tall buildings offer a fresh, modern style made possible by advances in computer design and improvements in building materials.

Therefore, one of the key findings of this study is that Chicago's skyscrapers along open spaces are major elements of image formation. The image of some cities is associated with a natural setting or remarkable natural landscape, notably Vancouver, Seattle, Rio de Janeiro, Guilin, or Kyoto. Other cities are known for the character and beauty of their public parks, plazas, or boulevards: examples include London's Hyde Park, the San Marco Piazza in Venice, and the Champs-Elysees in Paris. Using locational data from social media platforms including Twitter, Facebook, and Instagram along with using imagery from Google Earth, fieldwork, direct observations, and surveys and combining insights from architecture and urban design literature, this study reveals that Chicago continues to be the quintessential skyscraper city. Chicago's skyscrapers evoke strength, simplicity, and history, all qualities deeply embedded in the city's character [32,33].

Collectively, Chicago skyscrapers improve the imageability of the city. Michigan Avenue is a powerful example of a commercial path and refined architectural edge facing Grant Park. The Chicago River path is a beautiful way to experience the city and its remarkable skyscrapers. The Loop's skyscrapers along public plazas and open spaces make it a quintessential commercial district. Over the past centuries, Chicago has inspired many writers, poets, architects, and city planners. It remains a mecca of skyscrapers and the pulse of American architecture and urban design. As many cities all over the world rush to construct tall buildings, Chicago remains an essential model to help better integrate skyscrapers into their respective cities.

\section{Toward Building a Tourism Plan}

The findings of this study may serve as an initial foundation for building a tourism plan. A follow-up study should be pursued to build a robust plan. At the early stage, planners may use the findings of this research to exploit Chicago's strengths and address key shortcomings. In this regard, the collected visitors' views about public spaces are essential. The best feedback often comes from users, and a study's participants offer a torrent of new ideas to build Chicago tourism. Of course, improving tourism engenders multiple economic benefits, including bringing dollars to local businesses, creating jobs, and increasing tax return to the city.

Primarily, findings of this study revealed the 10 most popular socio-spatial clusters in the City of Chicago. Therefore, planners should carefully study these areas to capitalize on their tourism potential. Several desirable qualities need to be maintained. Among the important qualities of these popular spaces are being open to the public and accessible. Admission is mostly free of charge and admission to events could be also free. For example, there are free summer festivals-Blues in June, Taste of Chicago in July, jazz over Labor Day and world music in September. The Millennium Park offers free music every day in summer. Navy Pier, Chicago Cultural Center, and Daley Plaza offer free concerts year-round.

Consequently, an inviting, vibrant downtown prevails. For example, massive crowds on Michigan Avenue often flow seamlessly into the Millennium Park and Maggie Daley Park. Visitors do not have to worry about paying or standing in long queues for purchasing tickets. They can easily walk in and exit via the many wide entrances surrounding these parks. Similarly, the permeability of the Chicago Riverwalk allows residents and visitors to walk around and enjoy the river freely and to flow into the Magnificent Mile, a vibrant shopping district that includes everything from affordable fashion to high-end boutiques. There are also plenty of dining choices to enjoy during even a fast stroll down Michigan. 
Diverse public spaces offer something for everyone-young and old, and entertainment programs support cultural diversity. For example, the Millennium Park caters to people of all ages, with amenities like the charming Lurie Garden, Crown Fountains, and Linear Pool. Similarly, while Maggie Daley Park is designed for children, it does offer spaces for adults to enjoy. Collectively, these qualities promote a truly inclusive public social life in the downtown. This is particularly appreciated since Chicago is renowned for its neighborhood segregation.

Upon identifying the most popular spaces, it is important to plan for their sustainability. It is likely that demand on these spaces will increase, and planners should assess their carrying capacity. As explained earlier, the social media is playing an important role in popularizing these spaces and it is expected that more people will visit them in the future. In response, planners should observe potential overcrowding and set scenarios for crowd management. Navy Pier is already crowded; feedback indicated the need for expanding it. Visitors complained about long queues to several features, including swings and the Ferris wheel. Comments proposed adding "micro Navy Piers at the north and south sides".

Planners should also arrange for increasing associated services in popular spaces. Findings indicated that there are already existing shortcomings in serving tourists. Visitors have voiced concerns about the lack of public toilets and parking. Affordability is also an issue. For example, provided parking in places such as the Millennium Park and Maggie Daley Park is perceived as expensive. Overall, the downtown offers abundant, exciting culinary adventures and grab-and-go eateries; "it offers a selection of options that even the pickiest eater will find delicious." However, some visitors indicated a scarcity of eateries in certain public spaces, such as in the Maggie Daley Park, Federal Plaza, and the eastern section of Riverwalk that connects to Navy Pier.

Planners should examine and monitor major corridors that link the identified social nodes. Findings indicated that certain routes, such as Michigan Avenue and Wacker Drive already suffer from massive auto-traffic congestion. In a similar vein, sidewalks are becoming overcrowded. During rush hours, a significant pedestrian-automobile conflict arises. This problem is most severe during the summer season when public spaces are in demand. Additionally, bike lanes are inadequate. They are often unsafe, given the large interrupting volumes of auto and pedestrian traffic. It is also cited that Divvy, Chicago's bike-sharing system, is expensive.

Overall, distances between social clusters are walkable; though, there is room for enhancement. For example, the distance between the Millennium Park and Museum Campus could be inconveniently walkable by the elderly or mobility challenged individuals. Consequently, planners may consider building a "heritage streetcar" along Lake Shore Drive to bridge distances. Generally, Chicago's lakefront is an incredible treasure, yet, it is underutilized. It can be enhanced by building tourist attractions along it.

Likewise, while the Grant Park's expanse of greenery offers both spatial relief and a "lung" for the entire downtown, comments indicated that the park is underutilized. There is little incentive for visitors to spend time in the Grant Park. The Buckingham Fountain is perhaps the only attractive feature that visitors use as a backdrop for their photographs. Even taking photographs as an activity is unfortunately limited to daytime, very few photographs showed the fountain's performance, displaying lights at night.

Consequently, the Grant Park is often perceived as a secondary place. People may go through it to reach walkways along Lake Michigan. In response, it is possible to envision retractable glass, all-season gardens, to be located strategically in the park. It is also possible to create Parisian-style plazas around these places, as some participants suggested. Another possibility to improve the usability of the park could involve introducing physical activities, therapeutic exercises, and workout programs open for the public. Increasing the type and number of activities will invite more people to the Grant Park and increase the opportunities to enjoy superb views of downtown Chicago from this location.

As a seasonal challenge, Chicago downtown does not offer visitors adequate protection from the elements. The summertime, when public spaces are most visited, experiences rain as well as 
intense sun. Many visitors are underprepared for such events, leaving them all wet or blistering with sunburn. As a remedy, adding enclosed retractable glass walls and roof, and placing canopies in strategic connective points may provide visitors with shelter.

Further, visitors have indicated concerns about limited nightlife in downtown Chicago. Most of the public spaces in downtown are designed for daytime use, thus there are opportunities to utilize existing spaces to ignite nightlife. In fact, this proposal is in line with the city's efforts to revive downtown. In the past two decades, downtown Chicago has witnessed an increase in both residents and visitors, who may subsequently participate in nightlife. Further, supporting activities after sunset may improve perceived safety. Streets that are humming with life and action are often perceived to be safer.

Similarly, the findings indicate that visits happen in the warmer seasons. Most photographs displayed the city during the summertime. Planners may think about reviving tourist activities during the winter season. Constructing more snow and ice-related art and entertainment to build on ice-skating activities that happen during Christmastime could be a starting point.

Interestingly, public art plays an exceedingly important role in reviving the downtown. Among the most popular art pieces are the Cloud Gate and Crown Fountains. These interactive artworks are the most photographed objects. They invite people to spend more time around them, thereby enlivening the surrounding areas. The high popularity of these places has encouraged people to hang around even after dusk. One way to strengthen these areas is to layer music events on the spatial attraction, that showcase Chicago's popular music such as blues and jazz. These activities could be extended into nighttime, and hence complement the free classical concerts held most nights at the Jay Pritzker Pavilion. The classical music which is integral to the two-month Grant Park Music Festival can certainly be built upon to include more genres and locations.

Chicago streets are often adorned by iconic public sculptures such as "cows," "benches," and "police horses". However, the study's findings indicated the need to improve the overall attractiveness of streetscape. For example, one suggestion was to place art murals on walls and concrete parking lots. Entrances of parking structures could also benefit from the same idea. Similarly, the "L" stations are unsightly, and public artwork and murals could enhance their appearance.

The above observations and recommendations represent a "patchwork" approach to the city tourism plan. Chicago, however, is renowned for "thinking big", a notion promoted by Daniel Burnham through his 1909 Plan. Burnham stated, "Make no little plans; they have no magic to stir men's blood and probably themselves will not be realized. Make big plans; aim high in hope and work, remembering that a noble, logical diagram once recorded will never die, but long after we are gone be a living thing, asserting itself with ever-growing insistency" (p.12 [34]). Bold ideas are needed to launch Chicago into the stratosphere of global tourism. According to gathered comments, examples of big ideas include creating a large under-water aquarium, building an island hotel right on Lake Michigan, and reconfiguring Chicago Skyline at night.

While the existing night skyline conveys traditional, "static" qualities, planners may think about "modernizing" it. The cities of Hong Kong and Singapore enjoy comprehensive design guidelines on lighting systems. Regulations recommend lighting systems to certain areas; for example, guidelines recommend using up-lights for large public buildings such as governmental buildings and museums because they project grandness. In a more trendy, fashionable, and up-scale shopping district, LEDs are recommended, for they project spectacular colorful lights that help to attract people. Design recommendations also indicate that authorities should consider using LED to highlight major city landmarks. Interestingly, the Hong Kong skyline features a Symphony of Lights Laser Show every night at $8 \mathrm{PM}$ that lasts for 14 minutes. The show engages 44 participating buildings on both sides of the Victoria Harbor accompanied by symphonic music. The HSBC Hong Kong headquarters building is one of the participating buildings in the show. The building incorporates 716 intelligent lighting units, including 450 Martin Professional Cyclo 03 color changing fluorescent fixtures in the glass stairwells; Martin Professional Exterior 600s and Exterior 200 fixtures on five levels; eight searchlights, and over 
one kilometer of LED lighting around the top. The Bank of China Tower, one of the most recognizable skyscrapers, which reaches $305 \mathrm{~m}(1,000.7 \mathrm{ft})$, also has an interesting lighting system that accentuates its bold exoskeleton. Other significant participating buildings are Two International Finance Center, Central Plaza, and the CITIC Tower. The collective special lighting effects of Hong Kong coupled with their reflections in water make it among the most favored skylines in the world. The city has been nicknamed the "city of lights".

Borrowing ideas from Hong Kong and Singapore is not too unrealistic. For example, recently, Laurence Geller, chairman and CEO of Geller Capital Partners, and Lou Raizin, founder of Broadway in Chicago, have proposed "a system of aerial glass gondolas that would give visitors an eyeful of the downtown cityscape, reaching from Navy Pier west, along the Chicago River, to Wolf Point, where the river splits into north and south branches" [35].

Nevertheless, the tourism experiences of Chicago should remain unique, authentic, and novel. It is not recommended to create a Las Vegas or Disneyesque adventure. It is Chicago tradition, however, to blend authenticity and technology, and this could be a healthy guiding theme for a tourism plan. The provided ideas may kindle the interest of Chicago tourism entrepreneurs. Chicago has been successful in drawing tourists by the millions. The rational next project is to invite more repeat visitors; i.e. visitors who always inquire about new exciting features in Chicago that lure them to visit the city again and again.

\section{Conclusions}

This paper illustrated the employment of multiple methods (social media, field surveys, and direct observation) to learn about the public's views on Chicago, the birthplace of skyscrapers. It focused on the spatial interplay between the vertical plane established by skyscrapers and the horizontal plane anchored by plazas and large open spaces. While the study employed multiple methods, it uncovered the potential of social media to inform about the spatial distribution and popularity of public spaces among masses of people.

Compared to other methods of inquiry, social media offers multiple advantages. First, people participate in social media activities free of charge. As such, affordability is not an issue for gathering large data, which is unusual in traditional research methods. The generated data is not only "big", but it gets bigger daily. In the same token, social media enables the generation of a sustained flow of data beyond the project life, contrary to the case in traditional data gathering projects. Second, social media engages people with their free will by using their free time. Researchers neither need to ask people to volunteer for the project nor plan or organize their engagement and work around their busy schedules. Likewise, it is free of time pressures: participants are not under pressure that arises in a traditional workshop setting, for example. Third, social media data are unbiased by a research agenda: participants engage spontaneously. Similarly, social media avoids issues related to sampling bias because it largely represents people of all walks of life, be it color, gender, age, educational background, occupation, or lifestyle. Therefore, building consensus about an issue in the context of research concerning an urban environment is obtained neutrally. In addition, analysis could be neutral. For example, in the project explained in this paper, GIS was a neutral tool that used public data to illustrate the spatial concentration of visited public places.

When social media teams up with other methods of inquiry such as field surveys and direct observations, the methods collectively draw out public input, promoting democratic expression and enhancing decision-making processes. They may give an indication about the increasing demand on public spaces in the city. Consequently, public officials and planners should continually examine and monitor social media data to plan for a city's future.

As demonstrated in this paper, the collected data indicated the areas that are most popular, and therefore, plans should observe an anticipated increased demand on these places so that carrying capacities are not exceeded. Planners need to set strategies to meet increased demands on visiting popular spaces, which is translated also into increased demands on public transport, mass transit 
stations, bike stations, transport sharing systems, amenities, services, restaurants, entertaining places, cultural institutions, theaters, museums, and the like. Assessing and monitoring demands will collectively inform about ways to improve tourism and the economy. This is particularly valuable given the rapid urbanization occurring globally.

\section{Limitations and Further Research}

This study remains incomplete and features limitations. As mentioned in the "Applied Methods" section, due to privacy considerations, the involved social media companies refused to provide any information other than the locational data of uploaded photographs. They removed attribute data, which would have enabled conducting keyword searches to examine the public's comments on photographs to infer greater insight into the studied issues. Language challenges also emerged, since some participants were not fluent in the English language, and similarly researchers were not fluent in participants' languages, such as Mandarin, Spanish, French, and German. However, new translating apps (e.g., iTranslate and Google Translate) were useful in providing immediate help for resolving arising language confusion during personal interviews. Future studies may attempt to glean more information from the Internet imagery and other popular social media platforms, such as WhatsApp, QQ, WeChat, QZone, Tumblr, and Google+. These future studies will help to validate the results of this research. The promise is that social media is growing rapidly, and more data will improve validity. Finally, a follow-up statistical study may shed new light on the initial findings of this research.

Funding: This research received no external funding.

Acknowledgments: The author would like to sincerely thank the Buildings journal's anonymous reviewers for useful comments. The author would like also to deeply thank Saadia Shah, a professional planner and writer, for editing the paper.

Conflicts of Interest: The author declares no conflicts of interest.

Credits: All maps and illustrations were created by the author. In addition, based on study findings, all photographs were retaken by the author.

\section{References}

1. Jachna, T. Cyburban Semiotics. First published at COSIGN 2004. Available online: http://citeseerx.ist.psu. edu/viewdoc/download?doi=10.1.1.738.6058\&rep=rep1\&type=pdf (accessed on 15 July 2019).

2. Zhang, S.; Han, B.; Wang, D.; Ouyang, Z. Ecological Wisdom and Inspiration Underlying the Planning and Construction of Ancient Human Settlements: Case Study of Hongcun UNESCO World Heritage Site in China. Sustainability 2018, 10, 1345. [CrossRef]

3. Sanofft, H. Visual Research Methods in Design; Van Nostrand Reinhold: New York, NY, USA, 1991.

4. King, S. Co-Design: A Process of Design Participation; Van Nostrand Reinhold: New York, NY, USA, 1989.

5. Nelessen, A. Visions for a New American Dream; American Planning Association: Chicago, IL, USA, 1994.

6. McClure, W.; Byrne, A.; Hurand, F. Visualization Techniques for Citizen Participation, in Wendy McClure, The Rural Town: Designing for Growth and Sustainability; The Island Press: New York, NY, USA, 1997.

7. Lynch, K. The Image of the City; MIT Press: Cambridge, MA, UK, 1960.

8. Nasar, J.L. The Evaluative Image of the City; Sage Publications: London, UK, 1998.

9. Boyarsky, A. Chicago a la Carte. In Urban Design Ecologies; McGrath, B., Ed.; Wiley Publisher: New York, NY, USA, 2013; Chapter 04.

10. Kadar, B.; Gede, M. Where Do Tourists Go? Visualizing and Analyzing the Spatial Distribution of Geotagged Photography. Cartogr. Int. J. Geogr. Inf. Geovis. 2013, 48, 78-88. [CrossRef]

11. Whyte, W.H. The Social Life of Small Urban Spaces; Edwards Brothers: Baltimore, MD, USA, 1980.

12. Pickle, J. (Ed.) Ground Truth: The Social Implications of Geographic Information Systems; The Guilford Press: New York, NY, USA, 1994.

13. Li, Y.; Ye, Y.; Xiao, L.; Xu, W.; Law, A.; Wang, D. Classifying community space at a historic 412site through cognitive mapping and GPS tracking: The case of Gulangyu, China. Urb. Des. Int. 2017, 22, 127-149. [CrossRef] 
14. Li, D.; Zhou, X.; Wang, M. Analyzing and visualizing the spatial interactions between tourists and locals: A Flickr study in ten US cities. Cities 2018, 74, 249-258. [CrossRef]

15. Lieberman, M. The Most Popular Cities on Instagram in 2017. Travel and Leisure. 29 November 2017. Available online: https://www.travelandleisure.com/photography/instagram-cities-2017 (accessed on 15 July 2019).

16. Snavely, N.; Seitz, S.; Szeliski, R. Modeling the World from Internet Photo Collections. Int. J. Comput. Vis. 2008, 80, 189-210. [CrossRef]

17. Modsching, M.; Kramer, R.; Hagen, K.T.; Gretzel, U. Using Location-Based Tracking Data to Analyze the Movements of City Tourists. Inf. Technol. Tour. 2008, 10, 31-42. [CrossRef]

18. Girardin, F.; Fiore, F.D.; Ratti, C.; Blat, J. Leveraging Explicitly Disclosed Location Information to Understand Tourist Dynamics: A Case Study. J. Locat. Based Serv. 2008, 2, 41-56. [CrossRef]

19. Shoval, N.; McKercher, B.; Ng, E.; Birenboim, A. Hotel Location and Tourist Activity in Cities. Ann. Tour. Res. 2011, 38, 1594-1612. [CrossRef]

20. Pettersson, R.; Zillinger, M. Time and Space in Event Behaviour: Tracking Visitors by GPS. Tour. Geogr. 2011, 13, 1-20. [CrossRef]

21. Ganesh, L. A Study on Impact of Photography in Social Networks Users in Tamilnadu. SSRG Int. J. Commun. Media Sci. (SSRG-IJCMS) 2014, 1, 1-5.

22. Capistrán, J.B. Mobile Photography and Social Networks: Production, Consumption, Socialization and Copyright Practices Among University Students. Journal. Mass Commun. Q. 2016, 6, 512-522. [CrossRef]

23. Kia-Keating, M.; Capous, D.; Liu, S.; Adams, J. Using Community-Based Participatory Research and Human-Centered Design to Address Violence-Relasted Health Disparities Among Latino/a Youth. Fam. Community Health 2017, 40, 160-169. [CrossRef] [PubMed]

24. Lieberman, M. The Most Popular Cities on Instagram in 2017. Travel Leis. 2017.

25. Bachrach, J.S. The City in a Garden: A History of Chicago's Parks, 2nd ed.; Center for American Places Press: Chicago, IL, USA, 2012.

26. Bruegmann, R. Art Robert Deco Chicago: Designing Modern America; Yale University Press: New Haven, CT, USA, 2012.

27. Smith, C.S. The Plan of Chicago: Daniel Burnham and the Remaking of the American City; the University of Chicago Press: Chicago, IL, USA, 2006.

28. O'Gorman, T.J. Architecture in Detail; PRC publishing: Chicago, IL, USA, 2003.

29. Al-Kodmany, K. The Vertical City: A Sustainable Development Model; WIT Press: Southampton, UK, 2018.

30. Al-Kodmany, K. Understanding Tall Buildings: A Theory of Placemaking; Routledge: New York, NY, USA, 2017.

31. Heller, J.; Manus, C.; Nikitas, C. San Francisco: Promoting tall buildings through sustainable incentives. In Proceedings of the 8th CTBUH World Congress on Tall \& Green: Typology for a Sustainable Urban Future, Dubai, UAE, 3-5 March 2008; pp. 373-379.

32. Owen, D. Green Metropolis: Why Living Smaller, Living Closer, and Driving Less Are the Keys to Sustainability; Penguin Group: New York, NY, USA, 2009.

33. Wu, F.L. China's eco-cities. Geoforum 2012, 43, 169-171. [CrossRef]

34. Burnham, D.; Bennett, E.; Moore, C. Plan of Chicago; The Commercial Club: Chicago, IL, USA, 1909.

35. Koziarz, J. Hotelier keeps pushing for aerial tramway to Navy Pier. Curbed Chicago. 22 March 2018. Available online: https://chicago.curbed.com/2018/3/22/17138728/chicago-river-gondolas-skylinetransportation (accessed on 15 July 2019).

(C) 2019 by the author. Licensee MDPI, Basel, Switzerland. This article is an open access article distributed under the terms and conditions of the Creative Commons Attribution (CC BY) license (http://creativecommons.org/licenses/by/4.0/). 